London. The exhibition included a weather-forecasting unit at which a special souvenir weather report and forecast was compiled, and more than 150,000 copies were sold to visitors. The overall strength of the Office staff decreased from 2,601 to 2,589 during the year; but the scientific officer class increased from 160 to 165 . A number of university students, mainly of physics and mathematics, worked in the research centres of the Office during vacations.

\section{DRYING OF HIDES AND SKINS}

$I^{\mathrm{T}}$ is twenty years since experimental work in Kenya yielded results which established principles for the correct drying of hides; the experience gained since that time has now been described by J. R. Furlong, principal of the Colonial Products Advisory Bureau (Plant and Animal) (Colonial Plant and Animal Products, 2, No. 4 ; 1951).

To obtain the best possible leather from a hide, it is desirable to proceed to the tanning operations without reducing the hide to a dry state. Many countries, however, have insufficient native hides for their needs, and it is necessary to bring supplies from overseas or long distances to the tanneries. The distance which green or lightly salted hides can safely travel without damage caused by putrefaction is very limited, and it is essential to submit the hides to some process of curing in order that they may be transported and stored without deterioration. The curing may consist of salting the hide and transporting it in a wet-salted condition-an expensive method applicable to the best qualities of hides, or the material, after salting, may be dried out and sent to the market in a dry-salted condition. In many countries, however, salt is scarce and the use of the imported material would be too costly. Recourse is therefore made to the procedure of airdrying as a method of preservation. This is practised in many hot countries, particularly in the African continent. Dry hides represent a large proportion of the production of the entire output of such countries as Nigeria, East Africa, South Africa, the Sudan and Abyssinia, while India and South America are also large producers of dry hides.

Dry hides are an important class of raw material for the tanneries of the world to-day. In the decade before the War many tanners had developed a technique for producing leather of the highest quality from this class of hides, and during the War a still larger number of tanners in the United Kingdom were forced to use Colonial dry hides for the first time. While Continental tanneries had always handled Colonial hides, it is the great advance which has been made in this connexion in the United Kingdom, as a result of war-time experience, that is of significance. Tanners have learnt how to obtain good results, and it is to Colonial sources that English tanneries now look for increasing supplies of their raw materials.

The article describes methods which are now being used in the suspension-drying of cattle, goat and sheep skins, and emphasizes that the old method of drying hides and skins on the ground is liable to cause serious damage, and should never be employed. Drying hides and skins on the ground should be prohibited in areas where the improved processes of suspension-drying are practicable.

\section{HANDLING OF RADIOACTIVE AND TOXIC SUBSTANCES}

$\triangle \mathrm{N}$ edited report of the proceedings of the symA posium on the handling of radioactive and toxic substances, which was organized by the Chemistry Division of the Atomic Energy Research Establishment, Harwell, and which was held in two sessions on September 10-11 and 13-14, 1951, at Buckland House, near Faringdon, Berks, has recently been issued*. Sixty-four representatives from the chemical industry, universities, hospitals, government research establishments and the atomic energy projects of Western European countries attended. A list of the various representatives and their respective organizations is included in the report. The chairman, Dr. R. Hurst, welcomed the representatives, and mentioned that the original suggestion to hold such a symposium came from Dr. R. Spence, the head of the Chemistry Division at Harwell.

The contributed papers and subsequent discussion centred around three topics: the use of glove boxes, remote control of chemical operations and laboratory housekeeping and decontamination. Dr. Hurst, who spoke first, described the various improvements and requirements in the design of glove boxes which experience of their use at Harwell has indicated. $\mathrm{He}$ stated that glove boxes provide the simplest means of confining a chemical operation so as to prevent the spread of radioactivity, or to exclude oxygen, dust or harmful organisms. Suitable gloves developed for use in these boxes were described and shown. The use of heat-sealed polyvinylchloride bags for the transfer of active material or apparatus into or out of glove boxes was recommended. Mr. J. G. Bell then gave details of a glove box design with doublewall protection for work on alpha-active materials which require a protective atmosphere, and $\mathrm{Mr}$. W. G. Busbridge discussed the requirements of filters for use with glove boxes. The disadvantages of woolresin filters were pointed out, and a new type of filter employing a mechanical filter of wool and asbestos was briefly described.

On the subject of remote control of chemical operations, the discussion centred on two general methods : systems of tongs, manipulators and periscopes, by which conventional apparatus can be used by an extension of the hands; and systems by which liquids can be transferred, precipitates removed and similar operations conducted by vacuum-lifting or by pumping from vessel to vessel. In this section papers were read by J. Dean and A. B. Ritchie, G. B. Cook, G. N. Walton, G. Wortley, and Dr. W. J. Arrol. Finally, Dr. G. L. Miles reviewed the general problem of laboratory management in radiochemical work, the housekeeping techniques which are essential to prevent and restrict the spread of radioactivity and to keep the working-space clean and free from contamination. It was emphasized that hoods, glove boxes and apparatus should have hard smooth surfaces, that detergents are generally satisfactory as decontaminants and that certain radioisotopes may need special treatment. Recommendations on the disposal of active waste were also made.

The report makes interesting reading and is amply illustrated by photographs and diagrams.

* Atomic Energy Research Establishment. Symposium on the on September 10-11 and September 13-14, 1951, at Buckland House, neas Faringdon, Berkshire, (A.E.R. C R P58.) Edited by G. R. Hall. Pp. iv $+37+31$ pl. (Iondon: H.M.S.O., 1952.) 128. $6 d$. net 